\section{Examining the effects of tobacco control policy on low socioeconomic status women and girls: an initiative of the Tobacco Research Network on Disparities (TReND)}

\section{Deborah L McLellan, Nancy J Kaufman}

This commentary focuses on the convening of a national meeting of experts to develop a research agenda for investigating the effects of tobacco control policies on low socioeconomic women and girls.

li the USA and most of the industrialised world, tobacco use is highest among those with the lowest socioeconomic status (SES). While levels of education, income, and occupation are often used to define SES; gender, race, and ethnicity often intersect with these traditional measures as important additional characteristics of low SES Women and people of various racial and ethnic minorities are well represented among those of low SES, who as a group suffer the most from tobacco related health disparities. Those of low SES tend to have high rates of smoking and low rates of quitting success, are likely to suffer disproportionately from tobacco related deaths, and have children who are likely to start smoking. ${ }^{1-3}$

Tobacco control policies aimed at reducing the toll of tobacco addiction have been promoted across the USA and elsewhere. Although there is evidence suggesting that smokefree workplace policies have reduced overall secondhand smoke exposure, and tobacco taxes have been found to reduce the prevalence of smoking in the general population, little is known regarding the impact of such tobacco control policies on subpopulations such as low SES women and girls. It is vitally important to understand fully the impact of tobacco control policies on the most vulnerable segments of the population, who often have the least amount of resources to live smoke free.

The 2001 US surgeon general's report on women and smoking called for a better understanding of the effects of tobacco control policy on subpopulations of women, including those of low SES. ${ }^{3}$ In 2003, the National Cancer Institute (NCI) convened a large international meeting of its Women, Tobacco, and Cancer Working Group that recommended the need to "[conduct] research to explore and strengthen the positive health impacts of public and private tobacco control policies on women and girls, especially in populations at greatest risk" (page 13). ${ }^{4}$ In 2005, a second NCI report, "Eliminating Tobacco-Related Health Disparities Summary Report" ${ }^{\prime \prime}$ recommended further study of SES and its relation to smoking initiation and cessation, including the differential impacts of tobacco policies on disparate populations. These US activities paralleled work conducting gender and class analyses of tobacco control policies occurring in Canada and the European Union. ${ }^{67}$

The critical need for better understanding and more research in this area prompted the Tobacco Research Network on Health Disparities (TReND), funded by the NCI and the American Legacy Foundation, to launch in 2004 the first ever US initiative to explore the effects of tobacco control policies on low SES women and girls. The initiative includes three important activities: a review of current knowledge, development of this special issue of the Journal of Epidemiology and Community Health, and the convening of a national meeting of experts to develop a research agenda. This commentary focuses on the national meeting.

Before the meeting, a call for abstracts was sent to a group of policy researchers, practitioners, and advocates with the understanding that if their abstracts were accepted, they would be presenting at the September 2005 meeting and contributing their papers to this special peer reviewed journal issue. Original unpublished papers, as well as review and theoretical papers, were sought that addressed the impacts that tobacco control policies have on tobacco use, exposure to tobacco smoke, or other outcomes among low SES women and girls. Policies examined could be implemented at the individual (home), organisational, or societal levels. Although the papers needed to address the intersection of class and gender, additional analyses could examine the heterogeneity of low SES women (exploring group to group differences).

The meeting "Tobacco control policies: Do they make a difference for low SES women and girls?" convened on 22-23 September 2005 in Bethesda, Maryland, and was supported by a number of agencies within the US Department of Health and Human Services (DHHS) and the American Legacy Foundation. Within DHHS, funding came from the Office of Women's Health at DHHS, and the Division of Cancer Control and Population Sciences and the Office of Women's Health at NCI.

A diverse group of 50 people assembled, representing different disciplines, genders, racial/ethnic groups, geographical areas, and from different settings: state and federal agencies, advocacy organisations, foundations, and research institutions. The participants brought a wealth of knowledge and perspectives to enrich the discussions, and also served as connectors to larger networks of contacts for dissemination efforts.

In addition to presenting and discussing the research papers, the September meeting focused on identifying gaps in the research, developing priority areas for research (available at http://www. tobaccocontrol.cancer.gov), and addressing strategies to promote future work and disseminate information. Discussions occurred in a two-day meeting, using a format that included plenary presentations and workgroup discussions.

The publication of these articles adds to the evidence base on the effects of tobacco control policies on low SES girls and women, it is a start, but not sufficient. We hope that additional research and activity will be stimulated from collaborations developed at the meeting, the publication of this special issue, and from dissemination efforts. We would encourage all researchers, practitioners, and advocates who are reading this special issue to help disseminate these findings, and to commit to building the evidence and advocacy base necessary to achieve a tobacco free world for all of the population, including low SES women and girls.

\section{ACKNOWLEGEMENTS}

The authors thank Lorraine Greaves for her comments on an earlier draft of this commentary, and the funding agencies for the meeting: the American Legacy Foundation, the Office of Women's Health at the Department of Health and Human Services (DHHS), and the Division of Cancer Control and Population Sciences and 
the Office of Women's Health at the National Cancer Institute.

National Cancer Institute, National Institutes of Health, US Department of Health and Human Services

National Cancer Institute Office of Women's Health

US Department of Health and Human Services Office on Women's Health

The American Legacy Foundation

The Tobacco Research Network on Disparities

$J$ Epidemiol Community Health 2006;60(Suppl II):ii5-ii6.

doi: 10.1136/jech.2006.052407
Authors' affiliations

D L McLellan, Dana-Farber Cancer Institute, Center for Community-Based Research, Jamaica Plain, Massachusetts, USA

N J Kaufman, Aurora Health Care, Milwaukee, Wisconsin, USA

Correspondence to: Ms D L McLellan, DanaFarber Cancer Institute, Center for CommunityBased Research, 196 Chestnut Avenue, Unit L, Jamaica Plain, Massachusetts 02130, USA

Deborah_mclellan@comcast.net

Competing interests: none.

\section{REFERENCES}

1 Barbeau EM, Krieger N, Soobader MJ. Working class matters: socioeconomic disadvantage, race/ ethnicity, gender and smoking in NHIS 2000 Am J Public Health 2004:94:269-78.
2 US Department of Health and Human Services. The health consequences of smoking: cancer and chronic lung disease in the workplace. A report of the surgeon general. Rockville, MD: US Department of Health and Human Services, Public Health Service, Office on Smoking and Health, $1985,1-18,115$.

3 US Department of Health and Human Services. Women and smoking: a report of the surgeon general. Rockville, MD: US Department of Health and Human Services, Public Health Service, Office of the Surgeon General, 2001:36-7, 64, 575.

4 US Department of Health and Human Services. Women, tobacco, and cancer: an agenda for the 21 st century. Bethesda, MD: National Cancer Institute, 2004:13.

5 US Department of Health and Human Services. Eliminating tobacco-related health disparities summary report. Bethesda, MD: National Cancer Institute, 2005:vii-viii.

6 Greaves L, Barr VJ. Filtered policy: women and tobacco in Canada. Vancouver, BC: BC Centre of Excellence for Women's Health, 2000:23, 53-6.

7 Bostock Y. Searching for the solution: women, smoking, and inequality in Europe. London, UK Health Development Agency, 2003:6-7. 